\title{
Configural association theory: The role of the hippocampal formation in learning, memory, and amnesia
}

\author{
R. J. SUTHERLAND \\ University of Lethbridge, Lethbridge, Alberta, Canada \\ and \\ J. W. RUDY \\ University of Colorado, Boulder, Colorado
}

\begin{abstract}
It is proposed that the hippocampal formation makes a unique contribution to memory by providing the neural basis for the initial acquisition and storage of configural associations among events. A distinction is made between two kinds of memory processes: a simple associative process, which does not depend on the hippocampal formation, and a configural associative process, which does. The simple associative system records the organism's experiences as changes in the strength of associations between elementary stimulus events. The configural associative system combines the representations of elementary stimulus events to construct unique representations and allows for the formation of associations between these configural representations and other elementary representations. In the present paper, the results of two experiments designed to test predictions of our theory are described. We then illustrate how the theory can be applied to explain a wide range of impairments that have been observed when learning and memory tasks have been employed to assess the effect of hippocampal formation damage. These include tasks that measure place learning, recognition memory, latent inhibition, serial-compound conditioning, discrimination-reversal learning, and stimulus-selection processes. The relationship of our position to some other views of hippocampal function is discussed, and we conclude with suggestions for future research.
\end{abstract}

Over the past 15 years, our knowledge about the hippocampal formation has exploded. It is fair to say that the information now available about the details of the anatomy, synaptic physiology, mechanisms of plasticity, and neurochemistry of the hippocampus is not matched by that for any other brain structure. Our understanding of the contribution the hippocampus makes to behavior is also impressive. There is now general agreement that the hippocampal formation makes an essential contribution to learning and memory, and about which kinds of behavioral tasks are likely to reveal impaired memory. Nevertheless, no general consensus has emerged about

This work was supported in part by grants to R. J. Sutherland from the Natural Science and Engineering Research Council and Medical Research Council of Canada and to J. W. Rudy from the National Science Foundation (BNS 8207654). The authors thank C. A. Bames, P. J. Best, L. Bourne, G. L. Chew, R. Eaton, G. Glass, B. E. Kolb, S. Maier, B. L. McNaughton, J. Ranck, I. Q. Whishaw, and J. Willner for their comments on an earlier version of this manuscript. The manuscript was written while Robert J. Sutherland was on sabbatical leave at the Department of Psychology, University of Colorado, Boulder, CO. He thanks C. A. Barnes and B. L. McNaughton for their hospitality and support during this time. Reprint requests should be sent to either author. Mailing addresses: Robert J. Sutherland, Department of Psychology, The University of Lethbridge, 4401 University Drive, Lethbridge, Alberta T1K 3M4, Canada, or Jerry W. Rudy, Department of Psychology, University of Colorado, Boulder, CO 80309. how to characterize the memory processes that are lost or spared when the hippocampal formation is damaged. Special unifying roles have been suggested for episodic memory, intermediate-term buffers to bridge temporal gaps between events, working memory, anxiety, declarative memory, spatial mapping, temporal mapping, storing neocortical cell-assembly addresses, spatiotemporal context labeling, tuning out irrelevant events, response inhibition, memory-retrieval operations, and consolidation. The list could go on.

This paper represents an attempt to develop a more unifying framework for understanding the contribution of the hippocampal formation to learning and memory. The claim we make is that the hippocampal formation is essential to the normal functioning of a learning and memory system specialized for the acquisition, storage, and retrieval of configural associations, and that the loss of the processing afforded by this system is responsible for the impaired learning and memory that accompany damage to the hippocampal formation.

To establish the plausibility of our claim, we will present our argument in several stages. First, we will develop the concept of a configural association and distinguish it from the concept of a simple association. Next, we will present the data from two experiments designed to test predictions derived from our formulation. We will 
then review the existing literature, albeit not exhaustively, to show that our theory provides a plausible explanation of a wide range of behavioral impairments that have been observed in animals with hippocampal-formation damage. Finally, we will relate our theory to others in the literature and conclude by offering a prospective view.

\section{SIMPLE AND CONFIGURAL ASSOCIATIONS}

In this section, we develop the concept of a configural association and distinguish it from the concept of a simple association. As an introduction to the distinction between simple associations and configural associations, consider a Pavlovian conditioning example in which a subject experiences a compound stimulus consisting of a light $(\mathrm{L})$ and tone $(\mathrm{T})$ paired with the presentation of food $(\mathrm{F})$. As a consequence of this experience, the LT compound acquires the capacity to evoke a conditioned response. We can provide two different descriptions of the associations that might mediate conditioned responding. On the one hand, conditioned responding evoked by the compound may reflect the combined influence of two independent simple associations, one involving neural representations of the light and the food stimuli, the other involving the representations of the tone and food stimuli. On the other hand, one might suppose that a neural representation of the unique stimulus pattern or configuration initiated by the LT compound is associated with food and controls conditioned responding. Thus, within the configural association (hereafter represented as $<>$ ) in this example, the stimulus controlling behavior consists of a unique neural representation constructed from the combined representations of elementary stimuli, the light and tone, and associated with food $(<\mathrm{LT}\rangle-\mathrm{F})$. The general point that should be appreciated is that in every case, in either Pavlovian or instrumental conditioning, the configural representation involves a controlling cue composed of two or more elemental stimuli that stand in a specific relationship to one another. ${ }^{1}$ The possible relationships include, for example, simultaneous occurrence, sequential occurrence, or relative location. Once constructed, the configural representation can participate in associative processes and control behavior just as do the representations of the individual events from which it was constructed.

We assume that simple and configural associations depend on different sets of learning and memory systems for their acquisition and storage. We will call one set the simple association system (SAS) and the other the configural association system (CAS). Although these two systems are assumed to share many neural components, they differ fundamentally in the involvement of the hippocampal formation. The CAS depends critically on the integrity of the hippocampal formation, whereas the SAS does not.

\section{The Simple Association System}

In characterizing the SAS, we can draw on a rich tradition in animal learning theory that has its origins in the work of Thorndike (1898), Spence (1936), and Hull (1942), as well as modern representatives such as Rescorla and Wagner (1972). These theorists share the view that the organism's world can be fractured into a number of stimulus elements, features, or attributes, and that experience can alter how the organism responds to its environment by the strengthening and weakening of "simple associations" among these elements.

In order to understand the contribution of learning to behavior, one has to know not only the rules governing the strengthening and weakening of the simple associations, but also the ways in which multiple simple associations combine to influence behavior in complex situations. Spence's (1936) account of discrimination learning was the first detailed attempt at this kind of theorizing; it remains a useful vehicle for our purposes. In this formulation of the way in which an SAS operates, discriminative behavior is the result of a particular performance rule for how simple associations can be combined to influence behavior. Specifically, like Spence and others (e.g., Rescorla \& Wagner, 1972), we assume that the associative strength of a stimulus compound is the algebraic sum of the associative strength of its elements. In discriminationlearning situations, behavior will be controlled by the compound with the greatest associative strength. In a Pavlovian conditioning situation, the magnitude of the conditioned response will be monotonically related to the associative strength of the compound. Two compound stimuli can share common elements, but as long as there is a single perceptible element differentially associated with the trial outcome, by the combinatorial performance rule, an SAS will allow an organism to learn to behave differentially toward the stimulus compounds. Like Spence, but unlike Rescorla and Wagner (1972), we assume that the associative strength of each elementary stimulus on a learning trial increases or decreases as a linear function of the difference between its existing associative strength and the asymptotic associative strength possible.

\section{The Configural Association System}

The CAS differs fundamentally from the SAS in how it records and stores the organism's experiences. Whereas experiences are recorded in the SAS as changes in the strengths of associations among the representations of stimulus events, the CAS combines the representations of the elementary stimulus events to construct unique representations, and it stores associations between the configural representation and elementary representations.

In many cases, the capacity to acquire simple associations is sufficient to permit the organism to learn to respond discriminatively to its environment. For example, an animal could easily learn to respond discriminatively to one auditory stimulus (A1) paired with food and to a different auditory stimulus (A2) followed by no food, simply by associating the $\mathrm{Al}$ and food representation (F1) and the $A 2$ and no-food representation (F2).

Suppose, however, that the relationships of $A 1$ and $A 2$ to $F 1$ and $F 2$ varied, depending on the presence or absence of a light (L), so that in the presence of the light, A1 sig- 
naled $F 1$ and $A 2$ signaled $F 2$, whereas in the dark (D), the meanings of $A 1$ and $A 2$ were reversed so that $A 2$ signaled $F 1$ and $A 1$ signaled $F 2$. Note that no combination of simple associations would allow the animal to behave appropriately in response to $\mathrm{A} 1$ and $\mathrm{A} 2$. Thus, an animal with only an SAS would be in hopeless conflict when confronted with A1 or A2. By acquiring configural associations involving $\langle\mathrm{LA} 1\rangle,\langle\mathrm{LA} 2\rangle,\langle\mathrm{DA} 1\rangle$, and $<\mathrm{DA} 2\rangle$, along with $\mathrm{F} 1$ or $\mathrm{F} 2$, however, an animal could learn to respond appropriately, because it could then discriminate between the occurrence of $\mathrm{Al}$ and $\mathrm{A} 2$ in the light as opposed to the dark.

We noted that a configural representation involves a controlling cue composed of at least two or more elementary stimuli. We assume, however, that once a configural representation has been constructed, it may be activated by one of the elemental components. For example, suppose an animal was conditioned to a compound stimulus involving a light and tone. We expect that the configural system would construct a representation of the light and tone, and that either the light or the tone presented alone would have some capacity to access that representation and the behavior it controls.

\section{Interaction of the Two Systems}

It is likely that the SAS and CAS interact to determine performance in ways that are presently not well understood. We make two assumptions. First, in any situation, information about the organism's experience is stored in both systems. This is to say that the two systems operate in parallel. Thus, if the hippocampal formation is damaged or the information residing in it is lost, we assume that the content of the SAS will then exclusively determine behavior: The animal will respond to the individual elements of its environment as a function of their combined excitatory and inhibitory strengths. Second, if a configural association has greater predictive accuracy than a simple association involving one of the relevant elements, then that simple association's output to response systems will be suppressed.

\section{EXPERIMENTAL SUPPORT}

We contend that the normal animal's experience is recorded in both the SAS and the CAS, whereas the animal with damage to the hippocampal formation is deprived of the CAS. Although the CAS does record the animal's experience in behavioral tasks used to assess the effects of hippocampal damage, it is also the case that the SAS is capable of mediating performance in many situations. In such instances, the animal's performance may be unaffected or minimally impaired by damage to its hippocampal formation. Consider, for example, the previously mentioned Pavlovian compound conditioning case. It should be obvious that animals with hippocampal damage would condition to the LT compound, because it could still acquire simple associations between tone and food and between light and food, and then would combine their associative strengths. It should also be obvious that an SAS would permit animals to learn to respond differentially to a light paired with food and a tone followed by no food.

Thus, to evaluate our theory directly, one must assess the behavior of animals with hippocampal damage in behavioral tasks that cannot be solved by the SAS. Woodbury (1943) introduced one such behavioral problem, sometimes referred to as the negative patterning discrimination, which has no obvious simple association solution and may allow us to uncover the contribution that the hippocampal formation makes to the acquisition and retention of configural associations. The negative patterning problem requires the animal to respond differentially to the compound (again, LT) and the stimulus elements that constitute it ( $\mathrm{L}$ and $\mathrm{T})$. The animal is reinforced $(+)$ in the presence of either individual element, but not reinforced $(-)$ in the presence of the compound $(\mathrm{L}+/ \mathrm{T}+/ \mathrm{LT}-)$. Thus, the subject must learn to respond in the presence of either element alone, but to withhold responding in the presence of the compound.

It is important to appreciate that an SAS, as described above, does not permit a solution to the negative patterning problem. Only associations between the elementary stimulus features can be strengthened and weakened in this system. Given only the SAS, responding to a compound will reflect an algebraic summation of the associative strengths of the elementary stimuli. In the negative patterning problem, the combined associative strengths of the elements can never be less than the associative strengths of each element. Thus, an animal with only an SAS should not learn to respond less to the compound than to the elements. An animal with a CAS, however, should be able to solve the negative patterning problem, because this system provides the animal with a unique representation of the compound $(<\mathrm{LT}\rangle)$, which can be differentiated from the representation of its elements ( $\mathrm{L}$ and $\mathrm{T}$ ). In fact, the negative patterning problem can be solved by dogs (Woodbury, 1943), rabbits (Bellingham, Gillette-Bellingham, \& Kehoe, 1985; Whitlow \& Wagner, 1972), and rats (Rescorla, 1972).

An important feature of the negative patterning task is that it belongs to a broader class of tasks, sometimes referred to as the exclusive-OR (XOR) problem. The solution to these tasks requires a nonlinear associative process (Barto, 1985; Kehoe, 1988). As Kehoe (1988) has recently noted, the fundamental challenge of the XOR problem is that "it is impossible to generate the appropriate reaction, namely no response, to the joint stimulus inputs by a summation of the responses attached to two stimulus inputs" (p. 412). Connectionist theorists have demonstrated that models containing simply a layer of input units connected directly to a layer of output units cannot "learn" to perform an XOR operation (although they can learn to perform simple AND or OR operations). The addition of a layer of "hidden" units with modifiable connections between "visible" input and output layers can provide a network with the ability to learn to perform XOR operations and operations requiring other higher- 
order relationships between stimulus input and response output (Ackley, Hinton, \& Sejnowski, 1985; Kehoe, 1988; Rumelhart, Hinton, \& Williams, 1986). In the connectionist models, it is the changes in the connection strengths in the layer of hidden units that reorganize the input pattern to allow the learning of more complex, nonlinear input/output relationships. There is a striking similarity between the computational role played by hidden unit layers in connectionist models and the associative role we have proposed for the hippocampal formation in reorganizing inputs from sensory systems.

A central prediction of our theory is that animals with damage to the hippocampal formation will not solve the negative patterning problem. To test this prediction, we (Rudy \& Sutherland, in press) adopted a discriminative operant procedure developed by Rescorla (1972) to study configural processes in normal rats. The discriminative stimuli were a light, a tone, and a light-tone compound stimulus. The rats were rewarded with a food pellet for barpressing in the presence of the light or tone alone and not reinforced for barpressing in the presence of the lighttone compound. Some of the rats were trained to solve the problem before surgery, and the others were naive at the time of surgery.

Lesions were made in half of the rats, using multiple, intrahippocampal injections of a neurotoxin solution containing kainic acid and colchicine. This combination of neurotoxins was used to take advantage of the selective toxicity of colchicine for hippocampal granule cells and of kainic acid for hippocampal pyramidal cells. Thus, these rats had extensive depletion of neurons from both the dentate gyrus and CA fields of the hippocampal formation (see Rudy \& Sutherland, in press). Control rats were treated similarly, except that no neurotoxin solution was injected. After approximately 2 weeks of recovery,

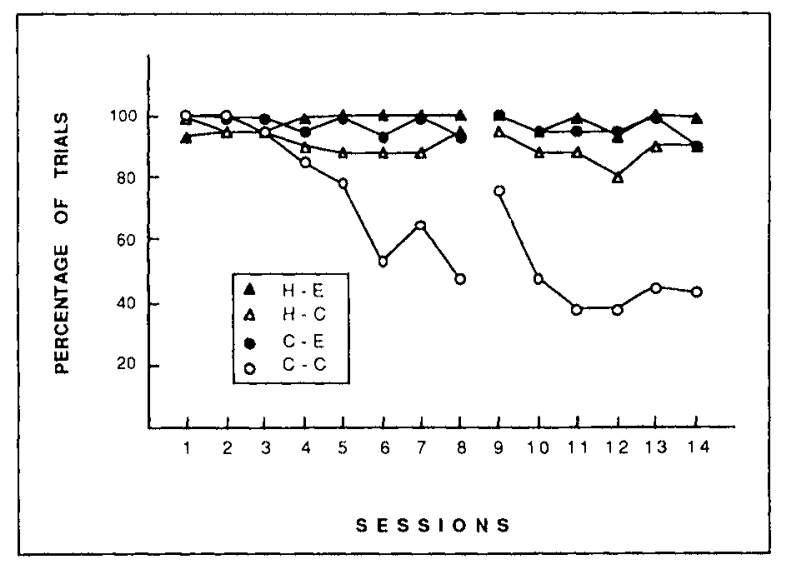

Figure 1. The mean percentage of trials animals responded to the tone and light elements alone $(\mathrm{E})$ and to the compound $(\mathrm{C})$ tone/light stimulus during the acquisition of the negative patterning discrimination. These animals were trained to respond to the tone and light alone before training on the negative patterning discrimination was initiated. There was a 5-day break between Sessions 8 and 9; otherwise the animals were trained on consecutive days.

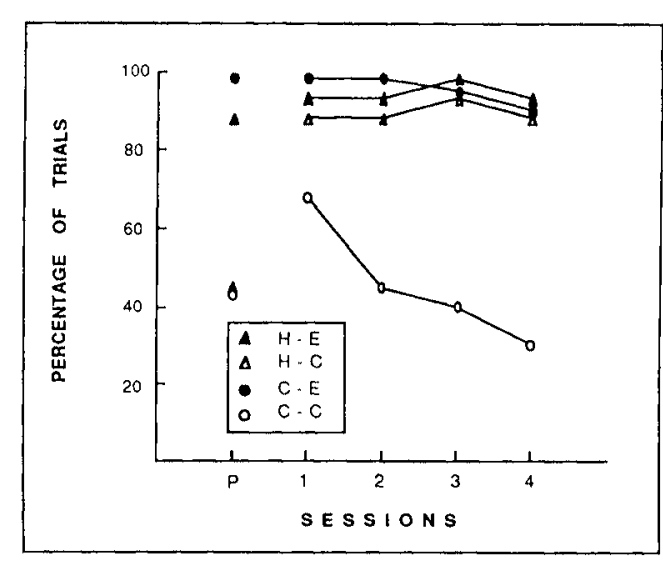

Figure 2. The mean percentage of trials animals responded to the tone and light elements alone (E) and to the compound (C) tone/light stimulus during the retention of the negative patterning discrimination. These animals were trained on the negative patterning problem prior to surgery. The first data point in this figure represents the mean percentage of trials on which the animals in each condition responded to the elements and to the compound prior to surgery. Note that there was no difference between the groups prior to surgery, and that both groups had solved the problem. The animals with damage to the hippocampal formation, however, displayed virtually no evidence of retaining this discrimination after surgery.

all the rats were tested in the negative patterning discrimination task.

The results were consistent with our predictions. The control animals readily learned to respond less to the compound than to the elements. In contrast, the animals with hippocampal-formation damage neither learned nor retained the negative patterning discrimination (see Figures 1 and 2).

An alternative account of these data is that animals with hippocampal-formation damage are generally unable to withhold responding (see Kimble, 1963). In fact, the animals with hippocampal-formation damage also responded more during the intertrial interval than did the control animals. Two additional observations, however, suggest that their failure to solve the negative patterning problem was not simply due to a general inability to withhold responding. First, these animals were able to learn to respond differentially to the reinforced light and nonreinforced tone. Second, their intertrial responding after learning this simple discrimination was not different from that of the control animals. Thus, the total package of results supports our hypothesis that the hippocampal formation is essential to the acquisition of configural associations.

\section{APPLICATION TO THE EXISTING LITERATURE}

Our task in this section is to demonstrate that our conception of hippocampal-formation function may provide a plausible explanation of a wide range of behavioral im- 
pairments found in animals with hippocampal-formation damage. If the organism must acquire configural associations to solve a particular task, then we expect it to be seriously impaired by hippocampal damage. It is important to note, however, that the majority of the literature is based on tasks that might be called "mixed configurals" - that is, they permit a solution based on the CAS, but they could also be solved by the SAS. To apply our theory to such cases requires that we present a plausible argument demonstrating how the CAS is important in instances in which hippocampal damage impairs performance, and how it is relatively unimportant in the instances in which no impairment is observed.

The existing literature relating hippocampal-formation damage to learning and memory is enormous. Thus, the application of our theory to this literature must necessarily be restrictive. In our review, we consider results from six categories of research: place learning, recognition memory, latent inhibition, Pavlovian serial-compound discrimination learning, discrimination-reversal learning, and stimulus selection.

Our choice of which categories of experiments to consider was guided in part by the importance of the data for some of the more prominent theories of hippocampal function, and in part because the existing influential theories do not explain the data from one or more of the categories very well. For example, the place-learning literature is central for the spatial-mapping theory of O'Keefe and Nadel (1978), and the recognition-memory literature is central for researchers engaged in developing a primate model of human amnesia. Although we will not develop a systematic critique of each of the current theories, we do note that: (1) the working-memory theory of Olton, Becker, and Handelmann (1979) does not apply well to some of the examples described in the placelearning, recognition-memory, stimulus-selection, and latent-inhibition categories; (2) the spatial-mapping theory of O'Keefe and Nadel (1978) can accommodate our examples from the place-learning and latent-inhibition categories, but it does not work well for examples from the stimulus-selection and discrimination-learning categories; (3) Rawlins' (1985) temporary memory-buffer account does not work well for examples from the latentinhibition, discrimination-learning, and stimulus-selection categories; and (4) without additional assumptions, Squire's (1987) declarative-memory theory does not apply well to any category if nonlinguistic species are used as subjects.

We have included experiments in which the hippocampal formation was damaged by electrolytic, aspiration, or neurotoxin lesions, or fornix/fimbria transection. The latter lesion almost entirely spares the hippocampal formation and the extensive afferent and efferent connections through the retrohippocampal area. Fornix/fimbria transection may disrupt the normal functioning of the hippocampal formation sufficiently to produce behavioral deficits similar to direct hippocampal damage. However, the possibility should be kept open that the spared hippocampal connections can provide a basis for spared learn- ing and memory abilities. In this light, we view studies employing direct hippocampal-formation manipulations as being more appropriate for assessing hippocampal function.

\section{Place-Learning Tasks}

In a number of studies, the effect of damage to the hippocampal formation on place learning has been examined. In the tasks employed in such studies, the goal object commonly stands in a fixed location relative to the discriminable features of the distal-cue environment, but its location is not specified by any single proximal cue, nor can the subject locate it by traveling toward a single distal cue. The water-maze task (Morris, 1981) is an important and popular example. A rat is placed into a circular pool of water and required to locate an escape platform that is hidden beneath the surface of the water. On each trial, the escape platform is always in the same location relative to the cues outside the pool. Rats rapidly learn to navigate to the platform, taking nearly direct routes from any starting point in the pool. Damage to the hippocampal formation devastates performance on such place-learning tasks (Morris, Garrud, Rawlins, \& O'Keefe, 1982; Okaichi, 1987; O'Keefe, Nadel, Keightly, \& Kill, 1975; Sutherland, Kolb, \& Whishaw, 1982; Sutherland, Whishaw, \& Kolb, 1983), but it has little impact on their ability to locate goals associated directly with proximal cues such as the visible platform in the water-maze task (Morris et al., 1982; Okaichi, 1987).

Although it is plausible that under some circumstances, animals may be able to exhibit accurate place navigation on the basis of simple associations (cf. Restle, 1957), it is likely that the arimals solve this problem by using the spatial arrangement of the distal cues or the topographical relationship among them to guide their navigation (O'Keefe \& Nadel, 1978). The application of such a strategy is often referred to as spatial mapping. In our view, it requires an intact configural association system. This dependence arises because of two necessary processes involved in spatial mapping. First, the animal must create and store configural representations of the features of the room as they appear, with respect to specific locations. Second, in many situations, navigation to a goal involves the conditional linkage of specific movement sequences with specific "local views" of the environment. To appreciate this analysis, consider Figure 3. In this figure, $X$ marks the location of the goal, and A, B, and $\mathrm{C}$ are visible landmarks. Note that to navigate directly to the goal, the correct response trajectory is conditional upon the subject's starting location. One trajectory, R1, is appropriate if the starting location is $\mathrm{S} 1$; another trajectory, $R 2$, is appropriate if the starting location is $\mathbf{S 2}$. Depending on the starting location, the rat must swim away from or toward the same set of distal features. This description is similar to the account offered by McNaughton (1989).

No published studies on primates contain assessments of the effects of damage to the hippocampal formation on 


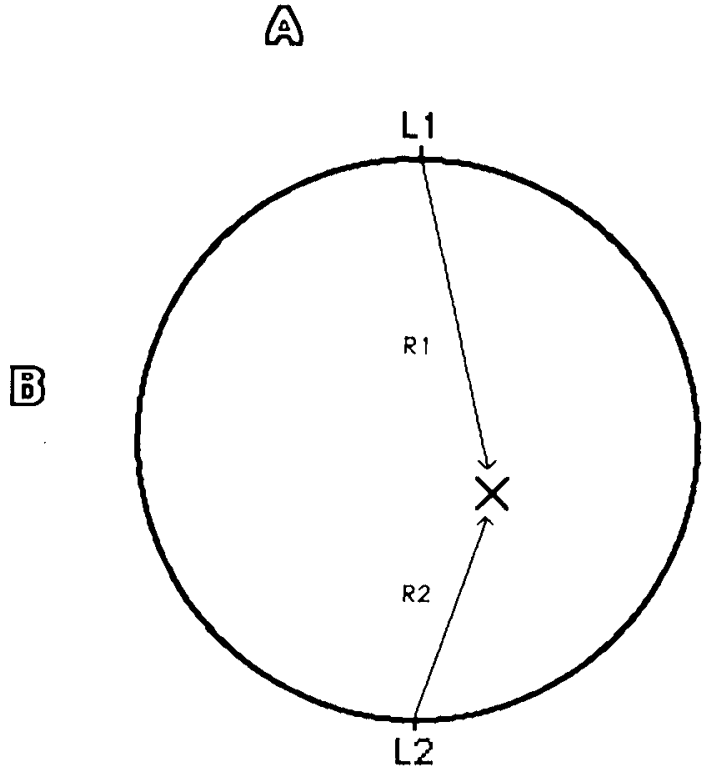

$\mathbb{C}$

Figure 3. A schematic representation of a place-learning task. The hidden goal is marked with an X. A, B, and C are visible landmarks, and $R 1$ and $R 2$ represent accurate trajectories to the goal from two different starting locations.

place-learning tasks that require the subject to move from one location to another. Primates with damage to the hippocampal formation, however, are impaired on placelearning tasks that have been studied using the Wisconsin General Testing apparatus (Jones \& Mishkin, 1972; Mahut, 1971; Mahut \& Cordeau, 1963). A recent study by Parkinson, Murray, and Mishkin (1988) provides the strongest support for our assertion. They trained monkeys on a location recognition-memory task that clearly requires acquisition of configural associations. In this task, the monkey is first given an information trial, during which it has to displace two different objects (A and B) that occupy two of three spatial locations. Next it is required to choose between two identical objects, either $A$ and $A$ or $B$ and $B$. The correct choice is conditional upon the location of that object on the preceding information trial. Specifically, in the choice trial, the monkey has to select the stimulus that is in the same location as it was on the information trial. Hippocampectomized monkeys could not solve this problem even though they had been trained in the procedure prior to surgery.

\section{Recognition-Memory Tasks}

Human amnesics with medial-temporal-lobe damage, including R.B., whose pathology was restricted to the CA1 field of the hippocampus, are impaired on recognitionmemory tasks (see Milner, 1970; Squire \& Cohen, 1984; Zola-Morgan, Squire, \& Amaral, 1986). Such tasks typically consist of two phases. First, the subject is presented a list of to-be-remembered items; these items are then re- presented, and the subject is required to indicate if they were on the original list.

Procedures also have been devised to study recognition memory in primates and rodents with experimentally induced brain damage. Gaffan (1974) introduced a task into the primate literature that has proved useful. Generally speaking, in his task, a trial consists of two episodes. First, the animal is exposed to a sample object (e.g., A); next, it receives a choice trial and is required to choose between the original and a novel object ( $A$ and $B$ ). Typically, the animal is rewarded on the choice trial for selecting the novel object. Once the task has been mastered, the animal is tested with varied intervals between the sample and the choice trial. Since no objects are ever repeated between trials, each choice is made between a familiar and a novel object. Thus, the procedure can be termed a trial-unique, delayed nonmatching-to-sample task.

Recently, Aggleton, Hunt, and Rawlins (1986) have developed a pseudo-trial-unique nonmatching-to-sample task to study recognition memory in rodents. In a Y-maze, rats are trained to choose between two distinct arms, one of which is identical to the arm chosen on the preceding trial, and is thus familiar, while the other arm is novel. The animal is rewarded for choosing the novel arm. The task is pseudo-trial-unique because Aggleton et al. (1986) employed 50 different pairs of choice arms and used a different pair on each trial.

The radial maze (Olton \& Samuelson, 1976), which has been employed to study hippocampal function, also may be viewed as a recognition-memory task. In the typical case, animals are allowed to choose without restriction between eight distinct arms, each of which is baited with food. A trial ends when the animal has consumed the bait in each arm. Errors are scored when the animal revisits an arm. Thus, good performance might be thought of as depending on the animal's recognizing a previously visited arm as being familiar, and only choosing to enter the novel or unvisited arms.

The studies of recognition memory in both the primate and the rodent present a mixed set of outcomes. For example, in Mishkin's laboratory, it has typically been found that monkeys with selective hippocampal-formation damage are only mildly impaired on recognition-memory tasks over delays of up to $200 \mathrm{sec}$ (Bachevalier, Saunders, \& Mishkin, 1985; Mishkin, 1978; Saunders, Murray, \& Mishkin, 1984). Mahut, Zola-Morgan, and Moss (1982), however, found that monkeys with damage to the hippocampal formation are significantly impaired, especially when the delay interval separating the sample and choice trials is 2 min. Most recently, Zola-Morgan and Squire (1986) have found that damage to the hippocampal formation produces a substantial impairment in the monkeys' performances on the stimulus recognition-memory task. The impairment increased as the retention interval between the sample and choice trials increased from $8 \mathrm{sec}$ to $10 \mathrm{~min}$.

Aggleton et al. (1986) found no evidence that rats with hippocampal damage were impaired on their pseudo-trial- 
unique delayed nonmatching-to-sample task. In their experiment, the delay interval varied between 0 and $60 \mathrm{sec}$. At similarly short delay intervals, primates with hippocampal damage are not impaired. Thus it would be important to know whether performance of rats with damage to the hippocampal formation would be impaired at longer intervals.

Studies with the eight-arm radial maze can be divided into two classes, those that employ the so-called spatial version and those that employ a nonspatial or cued version. In the spatial version, all arms are physically identical, and they can be discriminated from each other only with reference to the extramaze distal cues. In the cued version of the task, each arm is physically distinct. Barnes (1988) has recently reviewed this literature (e.g., Jarrard, 1983, 1986; Jarrard, Okaichi, Goldschmidt, \& Steward, 1984; Nadel \& McDonald, 1980; Olton \& Feustle, 1981; Olton \& Papas, 1979; Sutherland, 1985; Winocur, 1980) and has concluded that the evidence is overwhelming that animals with hippocampal damage are impaired on the spatial version of the task, whereas there is little evidence that these animals are impaired on the cued version of the task.

The mixed set of outcomes obtained after hippocampalformation damage suggests to us that the tasks used to study recognition memory in animals permit at least $t w o$ solutions, one that depends on an intact CAS and one or more alternative solutions that can be mediated by the SAS system. That hippocampal damage impairs performance on the spatial version of the eight-arm radial maze is to be expected, because it is a more elaborate version of the place-learning tasks that we have already argued should depend on the CAS. The trial-unique delayed nonmatchingto-sample and cued eight-arm radial-maze problems, however, require additional consideration.

Theorists such as Squire and Zola-Morgan (1983) have argued that normal recognition memory "requires the ability to recognize a stimulus object as one that was seen recently, or as one seen in a particular time and place" (p. 225). Implicit in this view is the idea that there may be more than one strategy or kind of information that is useful in solving recognition-memory problems. From our perspective, performance based on remembering an object in a particular time and place should depend on the configural associative system, because a unique "configural" representation of the to-be-recognized event and the exteroceptive and interoceptive stimulus elements constituting the situation in which the to-be-recognized event occurred must be created. Consequently, one strategy for solving recognition-memory tasks would be unavailable after damage to the hippocampal formation.

However, not all discriminations between objects recently encountered and unfamiliar objects require encoding of time and place. An alternative SAS solution, which does not depend on the hippocampal formation, may be based on the subject's reaction to novel stimuli. This can be illustrated by the trial-unique recognition-memory task used with primates, but it applies to the tasks with ro- dents as well. Note that in this task, the animal is always required to choose between a novel and a previously experienced object. It is reasonable to suppose that novel and experienced stimuli evoke different affective responses. We will term the response to a new stimulus $\operatorname{arl}$ and to an experienced stimulus ar 2 . We also assume that these affective attributes can enter into the control of choice behavior. Thus, on the choice trial, the functional stimuli include the physical attributes of the choice items and the evoked $\operatorname{arl}$ and $\operatorname{ar} 2$ attributes. Since the animal is always rewarded for choosing the stimulus that generates arl and is not rewarded for choosing the stimulus that generates ar 2 , the SAS could mediate correct performance in this situation. Prior exposure to one of the choice items for the animal employing this strategy functions primarily to determine whether it will evoke ar1 or ar2. It may be the case that this novelty-based strategy is available to the animal with hippocampal-formation damage and can mediate performance at least over short retention delays.

Thus, according to our analysis, an animal can use at least two different strategies to solve a trial-unique nonmatching-to-sample task-one that involves the CAS and the hippocampal formation, and another that can be mediated by the SAS and likely depends on neural structures other than the hippocampal formation. One implication of this analysis is that damage to some area of the brain besides the hippocampal formation may eliminate the novelty-based simple association solution.

Thus, it is instructive to note that a combined lesion of the hippocampal formation and amygdala devastates primate performance on the delayed nonmatching-to-sample task (Mishkin, 1978; Murray \& Mishkin, 1984; ZolaMorgan, Squire, \& Mishkin, 1982). It is also of interest that the amygdala has long been implicated as participating in affective processes and in the generation of the animal's unconditioned reaction to novel stimuli (Aggleton \& Mishkin, 1985; Bagshaw \& Benzies, 1968; Bagshaw \& Coppock, 1968; Goddard, 1964; Rolls \& Rolls, 1973; Wilson \& Rolls, 1987), although the amygdala's function is by no means limited to these processes. Animals with amygdala damage react to novel and previously experienced stimuli in the same way. They are both treated as if they were familiar (Nachman \& Ashe, 1974). These findings suggest that the amygdala might contribute to performance in recognition-memory tasks by providing the basis for a simple associative solution based on the animal's perceptual/affective reaction to novel as opposed to familiar stimuli. Animals with amygdala damage may not have discriminable $\operatorname{ar} 1$ and $a r 2$ reactions to novel as opposed to previously experienced stimuli.

A second implication of our analysis is that if the recognition-memory task is arranged so that the novelty strategy is not available to the animal, then selective hippocampal damage should produce a severe impairment. The recent findings of Raffaele and Olton (1988) support this assertion. They tested rats on a task similar to the one used by Aggleton et al. (1986), but instead of using a 
pseudo-trial-unique task with many different stimuli, Raffaele and Olton created a matching-to-sample task with only two visually distinct goalboxes. The animals received at least 30 trials per session with these stimuli; trials consisted of first forcing the animals to sample one stimulus and then permitting them to choose between the sample and the other stimulus. Since the animals were exposed to each choice item many times during a session, one would expect that, compared to results with the trialunique task, the relative novelty of the sampled item and its foil on a choice trial would have been so reduced as to render the simple associative solution based on the novelty strategy unavailable. This should have made performance on the task depend on the configural processes; consequently, it would have been more impaired by damage to the hippocampal formation. Consistent with our analysis, Raffaele and Olton (1988) report that damage to the hippocampal system devastated performance on this task.

\section{Latent Inhibition}

There is substantial evidence in the Pavlovian conditioning literature that repeatedly exposing the subject to a stimulus retards the rate at which that stimulus will acquire conditioned properties when it is subsequently paired with an unconditioned stimulus (Lubow, 1973). This phenomenon, however, which is termed "latent inhibition," can be eliminated by damaging the hippocampal formation (Best \& Orr, 1973; Kaye \& Pearce, 1987; Solomon \& Moore, 1975). It is not immediately obvious why the loss of configural associations should reduce the latentinhibition effect, unless one appreciates the fact that the latent-inhibition effect may be context-dependent. For example, Kaye, Preston, Szabo, Druiff, and Mackintosh (1987) have reported that there was a substantial latentinhibition effect when preexposure and conditioning occurred in the same context, but that conditioning proceeded as if the CS were novel when preexposure and conditioning occurred in different environments.

According to our view, the hippocampal formation is necessary for latent inhibition, because it creates the unique representation of the stimulus elements constituting the features of the preexposure environment and thereby allows an association to be formed between the configural representation of the context and the representation of the specific stimulus (see Nadel \& Willner, 1980, and Nadel, Willner \& Kurz, 1985, for a related view). The context dependency of latent inhibition makes it depend on the CAS. If cases of latent inhibition are reported that are not context-dependent, however, then our view predicts that damage to the hippocampal formation will not eliminate the effect of stimulus preexposure.

\section{Pavlovian Serial-Compound Discrimination Learning}

Ross, Orr, Holland, and Berger (1984) assessed the effects of damage to the hippocampal formation on the rat's ability to learn a Pavlovian serial-compound discrimina- tion, sometimes referred to as "occasion-setting." The serial compound consisted of a light followed $5 \mathrm{sec}$ later by a 5 -sec presentation of a tone that terminated with food $(\mathrm{L} \rightarrow \mathrm{T}-\mathrm{F})$. On other trials, the 5-sec tone was presented alone and not followed by food $(\mathrm{T}-$ ). Thus, the meaning of the tone was conditional upon the occurrence of the light. Control animals easily learned to respond differentially to the tone preceded by the light as compared to the tone alone, but animals with damage to the hippocampal formation never solved the discrimination. The animals with damage to the hippocampal formation, however, did solve an embedded, simple auditory discrimination (clicker paired with food, white noise with no food) just as readily as did the control animals. It is easy to imagine that the CAS could be important for solving this problem. The animal discriminates between the two kinds of tone presentations by forming a configural representation of the light-tone serial compound that differs from the configural representation of the tone alone.

It should be pointed out, however, that the serialcompound discrimination problem also permits a nonconfigural or an SAS solution. For example, the light in the $\mathrm{L} \rightarrow \mathrm{T}-\mathrm{F}$ versus $\mathrm{T}$ - serial-compound discrimination not only must be considered as a stimulus that can be configured with the tone, but also must be considered potentially capable of entering into a simple association with the US. As a consequence-to use conventional Pavlovian conditioning language-the light itself can directly acquire an excitatory association with the US that will summate with the tone's excitatory properties, so that the excitatory properties of the light and tone together will exceed that of the tone alone. This differential excitatory strength of the compound as compared to the strength of the single element could permit the animal to respond differentially. If the serial-compound discrimination were solved in this manner, we would predict that damage to the hippocampal formation would not impair performance. An important feature of the Ross et al. (1984) study was that their animals did not use the simple association strategy to solve the problem.

\section{Discrimination Reversal}

Although animals with damage to the hippocampal formation can learn a simple discrimination $(\mathrm{A}+/ \mathrm{B}-)$, they are often impaired when they must subsequently learn to reverse the discrimination $(\mathrm{A}-\mathrm{B}+\mathrm{B})$ (Berger \& Orr, 1983; Douglas, 1967; Douglas \& Pribram, 1966; Gaffan \& Harrison, 1984; Jones \& Mishkin, 1972; Mahut, 1971; Teitelbaum, 1964). Discrimination reversals are mixed configural tasks. An SAS could eventually solve discrimination reversals, because the change in the reward contingencies that the subject encounters during reversal would ultimately change the relevant simple associations needed to behave discriminatively in response to $\mathrm{A}$ and $\mathbf{B}$.

Hirsh $(1974,1980)$, however, has pointed out the conditional nature of discrimination reversals and explained why they may be sensitive to damage to the hippocampal 
formation. The general form of Hirsh's argument merits reconsideration here. Consider the case in which the animal is initially trained that approach to A will be rewarded and approach to $B$ will not $(A+/ B-)$. When the significance of $A$ and $B$ is reversed $(A-/ B+)$, the animal is faced with the same physical situation that prevailed in initial acquisition, but its meaning has changed. Hirsh (1974) suggested that there are discriminable temporal/ contextual cues (Hirsh called them contextual labels) correlated with the initial problem and its reversal that could be used to disambiguate the meaning of $A$ and $B$. We will call the contextual marker present during original learning $t 1$, and the marker present during reversal learning, $t 2$. Normal animals could use these markers to disambiguate the meaning of $\mathrm{A}$ and $\mathrm{B}$, but animals with damage to the hippocampal formation could not. We would argue that the representations of these contextual markers combine with the representations of $A$ and $B$ during reversal learning to create unique configural cues, $\langle t 2 \mathrm{~A}\rangle$ and $\langle t 2 \mathrm{~B}\rangle$, which can be discriminated from the configural representation of $A$ and $B$ during the original learning, $\langle t 1 \mathrm{~A}\rangle$ and $\langle t 1 \mathrm{~B}\rangle$.

The problem with this account is that although $t 1$ and $t 2$ are theoretically convenient, their physical basis is not specified. It may be, however, that a change in the animal's internal state accompanies the change from acquisition to reversal. For example, the change in the reward conditions associated with A and B during original training can be expected to produce a state of "frustration" during the early stages of reversal (Amsel, 1958, 1962), and the neural representation of this state change may be combined with the representations of $A$ and $B$ by the CAS to create representations of A and $B$ that can be discriminated from their representations during original training.

Hirsh, Leber, and Gillman (1978) have also provided support for the idea that internal state differences can serve this conditional/configural function (see also Hsiao \& Isaacson, 1971). They trained rats in a T-maze with food and water as the goal objects on alternate days. On the days when food was the reward, it was placed in one arm (e.g., the right arm), and on the days when water was the reward, it was placed in the other arm. The important aspect of this study is that on the days when food was the reward, the animals were food-deprived; on the days when water was the reward, they were water-deprived. Normal rats were able to learn to go right on food days and left on water days. Since only three trials per session were administered, and the rats had to reach the criterion of 11 out of 12 correct consecutive responses, the animals' choice performances had to be controlled by the internal cues associated with the two motivational states. It should be noted that animals with damage to the hippocampal formation were impaired in solving this problem.

\section{Stimulus-Selection Tasks}

The hippocampal formation makes an important contribution to a class of phenomena referred to as stimulus selection (e.g., see Rickert, Bennett, Lane, \& French, 1978; Rickert, Lorden, Dawson, Smyly, \& Callahan, 1979; Solomon, 1977; Winocur, Rawlins, \& Gray, 1987). These include the Kamin blocking effect (1969), the neutralization of common cues (Wagner, Logan, Haberlandt, \& Price, 1968), and the prevention of conditioning to contextual stimuli (Odling-Smee, 1975). The common feature of this class of phenomena is that normal animals can often be shown to condition less to a particular stimulus when there are other stimuli present that are better predictors of the unconditioned stimulus (US) than when no other better predictors are present.

As an example of this class, consider the classic study of Wagner et al. (1968). Their animals were trained to discriminate between two stimulus compounds constructed from one of two auditory stimuli (A1 or A2) and a light (L). On AlL trials, the reinforcer was presented (A1L+), but $\mathrm{A} 2 \mathrm{~L}$ trials were not reinforced (A2L-). It should be noted that the auditory cues are perfectly correlated with the reward contingencies, but that the shared light element might be described as irrelevant to the trial outcome-it was reinforced on only $50 \%$ of the trials. The animals solved this problem, but the important result Wagner et al. (1968) reported was that when the light alone was presented following training, it evoked very little conditioned responding.

The significance of this finding can only be appreciated in comparison with the behavior of the animals in a control condition. They were trained in a "pseudodiscrimination" problem. In this case, both the A1L and A2L compounds were paired equally often with reward and nonreward ( $11 \mathrm{~L}+,-$ and $\mathrm{A} 2 \mathrm{~L}+,-)$. Note that, just as in the true discrimination condition ( $\mathrm{A} 1 \mathrm{~L}+$ and $\mathrm{A} 2 \mathrm{~L}-$ ), the light is reinforced on only $50 \%$ of the trials. Following training in the pseudodiscrimination problem, however, the light alone evoked substantial responding, more than did the light cue of the true discrimination problem, and as much as did either $\mathrm{A} 1$ or $\mathrm{A} 2$.

Thus, when there are stimuli available that predict the occurrence of the reinforcer, as in the true discrimination problem (A1L+ vs. A2L-), there are processes available to the normal animal that have the effect of neutralizing the impact that irrelevant stimuli (i.e., the common light cue) have on behavior. Animals with hippocampal damage are unable to neutralize irrelevant cues. They condition as strongly to the common light cue of the true discrimination problem as they do to the common light cue of the pseudodiscrimination problem (Rickert et al., 1979).

From our perspective, the essential processing that neutralizes the normal animal's response to irrelevant cues depends on the CAS. The SAS provides the associative processes that allow the animal to acquire simple associations $(\mathrm{A} 1+, \mathrm{A} 2-, \mathrm{L}+,-)$; the CAS provides the animal with configural representations of the compounds ( $<$ A1L $>$ and $<A 2 L>$ ). The configural representations are clearly better predictors of reinforcer presentation than the representation of the single light cue within the SAS. 
On the basis of our assumptions about the interactions between the systems, the output from the simple light association circuitry will be suppressed. Thus, unless the SAS is released from suppressive influence, the normal animal should respond very little to the light alone following training on the true discrimination problem. Note that presentation of the light alone will tend to activate not only the suppressed simple associative circuitry, but also components of the two configural representations in which it figures. The content of the configural system will clearly have an indeterminate predictive value.

The situation is fundamentally different for the animal with hippocampal damage. It does not have the configural representations $<\mathrm{A} 1 \mathrm{~L}\rangle$ and $\langle\mathrm{A} 2 \mathrm{~L}\rangle$ available to it. Consequently, only the simple associative system is recording its experience, and this system cannot discriminate the light experience in compound with $\mathrm{A} 1 \mathrm{from}$ the light experience in compound with $\mathrm{A} 2$, or from the light presented alone. Thus, when tested following the acquisition of the true discrimination problem, the animal with hippocampal-formation damage should respond to the light alone more than the normal animal does. In the case of the pseudodiscrimination problem, the contents of the configural system predict reinforcer delivery no better than the contents of the simple systems. Therefore, there will be no suppression of simple association output, and, if the light is presented alone, rats with damage to the hippocampal formation will respond similarly to control rats.

As a caveat, we note that our position leaves open the possibility that animals which sustain damage to the hippocampal formation after having solved the AlL+ versus A2L-discrimination problem may also display as much responding to the common light element as the animals trained on the pseudodiscrimination problem. This is because we assume that the SAS in normal animals is working in parallel with the CAS, but that its influence on performance is suppressed when the configural associations make better predictions than do the simple associations. Damaging the hippocampal formation after learning may remove the suppressing effects of the configural system and reveal the content of the SAS. There are no data available to evaluate this possibility.

It is also of interest to consider another recent example by Winocur et al. (1987). They exposed normal rats and rats with damage to the hippocampal formation to Pavlovian conditioning in which a CS signaled the occurrence of shock. They then used the procedures of Odling-Smee (1975) to assess the amount of conditioning that accrued to the background contextual cues present during conditioning. Normal animals condition very little to the background if the unconditioned stimulus is preceded by a conditioned stimulus, especially in comparison with the amount of conditioning that occurs to the context if the US is presented alone, or unsignaled by the CS. In other words, the presence of the CS normally will reduce or prevent conditioning that otherwise will accrue to the context. Winocur et al. (1987) have reported the important result that animals with hippocampal damage showed excessive conditioning to the background even when the unconditioned stimulus was signaled by a CS. In other words, the presence of the CS fails to prevent conditioning to the background among animals with hippocampalformation damage.

We suggest that this result can be directly attributed to the absence of the CAS. By our account, the normal animal constructs configural representations of the CS together with some elements of the background, $\langle\mathrm{BCS}\rangle$, and this representation can be discriminated from the configural representation of the background alone, $\langle\mathrm{B}\rangle$. No such representations are available to animals with hippocampal-formation damage. According to this analysis, the presence of a CS will protect the background from conditioning, because the configural representation, $\langle\mathrm{BCS}\rangle$, predicts US occurrence, and $\langle\mathrm{B}\rangle$ is never paired with the US. In contrast, because the animal with a damaged hippocampal formation lacks these configural representations, conditioning will accrue to the elements that compose the background, independently of whether the US is signaled by the CS. Consequently, our position expects that these animals will condition more to the background than will normal animals.

\section{DISCUSSION OF THE APPLICATION}

We have illustrated how configural association theory can help us understand the difference between situations in which damage to the hippocampal formation produces learning and memory impairments and situations in which no impairment is observed. We suggest that the literature is consistent with the following empirical generalization and, consequently, with our theory: If the performance of an animal with hippocampal-formation damage is assessed with a task that cannot be solved on the basis of the rules governing the $S A S$, then a significant impairment will be detected.

Although we think our theory does a reasonable job in integrating a substantial portion of the existing literature, we would be remiss if we failed to point out some of the potential problems that may await the theory, and we have no doubt that the critical reader may find others. There is an impressive body of data from place-learning tasks, nearly all of it consistent with O'Keefe \& Nadel's (1978) cognitive map theory and also consistent with our theory. But there are very few studies on the effect of damage to the hippocampal formation on pure nonspatial configural tasks, for which the configural formulation and the map theory make different predictions. The results we obtained with the negative patterning problem (see Figures 1 and 2) are important for just this reason. More data of this sort, however, are needed for our position to be consolidated.

We should also point out that some potentially troublesome data exist. Gaffan et al. (1984), for example, have reported several experiments with fornix-transected monkeys. Some of their behavioral tests appear to be pure non- 
spatial configural tasks and not solvable on the basis of simple associations. The fornix transection, however, had little effect on the monkeys' performances in these tasks. These results might be seen as posing a problem for our theory. These experiments, however, may not be decisive, because Gaffan et al. (1984) did not remove the hippocampal formation, and we are not convinced that fornix transection has consequences for memory function that are equivalent to damage to the hippocampal formation. In fact, in human beings, damage to the fornix does not necessarily reproduce the same degree of memory impairment as does damage to the hippocampal formation (see Squire, 1987, p. 195). The fornix transection also produces much smaller impairments in the monkey than does direct damage to the hippocampal formation. This generalization applies to object recognition-memory tasks, object-reward association tasks, spatial recognitionmemory tasks, and concurrent-object discrimination tasks (Mahut \& Moss, 1986; Mahut, Moss, \& Zola-Morgan, 1981; Mahut et al., 1982; Moss, Mahut, \& Zola-Morgan, 1981). We note, as do many others, that a substantial proportion of the efferents from the hippocampal formation pass caudally through retrohippocampal areas, so that, on anatomical grounds, there is reason for doubting that fornix transection would produce the same deficits as would damage to the hippocampal formation.

We believe that the hippocampal formation is essential for both the acquisition and the storage of configural associations. In applying our theory to the literature, however, we have made no special attempt to marshal facts that support the assumption that the hippocampal formation is a storage site. This omission should not be construed to mean that empirical support is lacking. Instead, this should be viewed as a relatively separate and complicated issue. For example, retrograde amnesia has been observed when the hippocampus has been damaged after subjects have mastered place-learning tasks (Jarrard, 1983; Nadel \& McDonald, 1980; Sutherland, 1985), the serial-compound discrimination (Ross et al., 1984), and the negative patterning discrimination (see Figure 2). Although such data are consistent with a storage-site interpretation, there are alternative interpretations, such as the hippocampal formation's being an essential retrieval route through which the memory is accessed.

We also have not related our theory to the intriguing phenomenon of temporally limited retrograde amnesiathe fact that memories established more remotely in time from damage to the medial temporal lobe are remembered better than memories established more closely in time to the damage (Milner, 1959, 1962, 1970; Scoville \& Milner, 1957; Squire, Cohen, \& Nadel, 1984). Presumably, for retrograde amnesia to be temporally limited, something about remote memories, their organization, location, or other unknown characteristics is different from more recently established memories. The unknown process that is responsible for making remote memories resistant to retrograde amnesia treatments is often called "consolidation."' Squire et al. (1984) have suggested that the integrity of the medial temporal region for some period after the memory is established is essential for consolidation to occur.

We would add but a couple of points. First, we suspect that the kinds of memories that are subject to temporally limited retrograde amnesia are those that depend on the CAS for their initial acquisition. Second, we suggest that the integrity of the hippocampal formation in particular may be critical for the consolidation of these memories. Sutherland, Arnold, and Rodriguez (1987), in fact, have provided some data relevant to these points. They found that animals trained on the place-learning version of the Morris water task displayed better place navigation when the interval from training to surgery was 8-12 weeks than when it was only 1 week.

In fact, there have been surprisingly few studies designed specifically to study temporally limited retrograde amnesia (but see Salmon, Zola-Morgan, \& Squire, 1987). Consequently, there is much to be gained from well-designed studies. For example, where are the extrahippocampal storage sites? By means of what process are memories consolidated? Which hippocampal formation output route conveys the consolidating influence? What factors (age, amount of training, distribution of training, interpolated interference, etc.) influence the time course of consolidation? The list could go on.

\section{RELATIONSHIPS TO OTHER THEORIES}

The theory of hippocampal-formation function that we have advanced is built on a foundation of ideas about learning and memory that have been emerging continuously for several decades. In this section, we discuss our theory in relation to other theories. First, we will compare our memory taxonomy with others in the literature. Then we will relate our position regarding the mnemonic function of the hippocampus to other theories.

The idea that there is more than one learning and memory system is shared among a number of memory theorists. As a result of her analysis of human amnesics (Milner, 1959, 1962, 1970), Brenda Milner concluded that not all memory capacities are lost as a consequence of damage to the medial temporal region, which includes the hippocampal formation. According to her description, relatively short-term retention of verbal and nonverbal information, over a period of minutes, was intact (especially if the opportunity for " rehearsal" was permitted), and patients could show long-term retention of newly acquired skills or "habits"' (e.g., Milner, 1970). Spared capacities presumably do not depend on the medial temporal region. Squire and his colleagues (Cohen \& Squire, 1980; Squire, 1987) have elaborated on Milner's empirical and theoretical contributions by distinguishing between procedural and declarative memory systems.

Nadel and O'Keefe (1974) and Hirsh (1974) appear to be the first theorists to have made explicit the possibility that a dual memory-system approach could be valuable to the understanding of learning and memory impairments following brain damage in experimental animals. Hirsh distinguished between what he called performance line 
storage and memory (the latter he linked to the hippocampal formation). He further suggested that to recognize this distinction may provide a way of resolving the debate between the so-called $S-R$ and cognitive approaches to learning theory. He has been followed in this case by Mishkin, Malumut, and Bachevalier (1984) and Mishkin and Petri (1984), who have distinguished between habits and memories, each of which is subserved by a different neural system. In their influential book, O'Keefe and Nadel (1978) distinguished between taxon and locale memory systems, which also depend differentially on hippocampal function. Finally, we note that Olton, Becker, and Handelmann (1979) distinguished between reference and working memory, with only the latter being subserved by hippocampal function.

Like a number of other theorists (Hirsh, 1974, 1980; Mishkin et al., 1984; Mishkin \& Petri, 1984; Wickelgren, 1979), we have chosen to attribute the spared learning and memory abilities of organisms with medial-temporallobe damage to a system (SAS) that is capable of simple associative processing of the sort originally envisioned by Thorndike (1898) and subsequently developed by Spence (1936) and Hull (1942).

Our concept of the configural associative system as mediating the memory-dependent behaviors that are lost as a consequence of damage to the hippocampal formation also can be traced to the important insights of earlier theorists. In particular, the ideas put forth by Hirsh (1974, 1980), O'Keefe and Nadel (1978), and Wickelgren (1979) have much in common with our conceptualization. These theorists recognized that in some sense the hippocampal formation was especially critical for tasks that require solutions based on the relationship among the stimulus elements constituting the controlling cues, as opposed to the simple associations between a stimulus element and reward or nonreward (see also Grossberg, 1982).

O'Keefe and Nadel (1978) proposed that the hippocampal formation enabled the animal to acquire map-like representations of its environment, the map being composed of "a set of place representations connected together according to the rules which represent distances and directions amongst them"' (O'Keefe \& Nadel, 1979, p. 488). Their theory predicted that animals with damage to the hippocampal formation would be impaired in placelearning tasks, and, as our review of this literature has indicated, they were right.

Hirsh $(1974,1980)$ also emphasized the contribution of the hippocampal formation to relational operations. In particular, he spoke of conditional operations that the hippocampal formation performs, in which the meaning of the same physical stimulus can vary depending on the presence or absence of some other stimulus. Thus, he showed how relational information could be important beyond the spatial domain of O'Keefe and Nadel (1978). The recent finding by Ross et al. (1984) that damage to the hippocampal formation eliminates the rat's ability to solve a serial-compound discrimination was clearly anticipated by Hirsh's theory.
In some ways, Wickelgren's "chunking theory" of the hippocampal formation can be considered a predecessor to our theory. For Wickelgren, chunking is "a learning process by which a set of nodes representing constituents (components, attributes, features) of a whole comes to be associated to a new node that, thereby, represents the whole chunk' (Wickelgren, 1979). The node representing a chunk is conceptually similar to our concept of a configural association. Wickelgren's position clearly predicts the deficits we observed in rats with hippocampal damage in the negative patterning discrimination problem.

The position of Squire and Cohen (Cohen \& Squire, 1980; Squire, 1987) may also be viewed as having some features in common with our view. They limit the hippocampal contribution to declarative memory. Since declarative memory is defined by its accessibility to conscious recollection-its ability to be declared-it is not yet possible to determine how it should be applied to the kinds of relational information that nonlinguistic species can learn and remember. If, however, the way we have suggested that the CAS contributes to recognition memory is indeed the case, then one might speculate that the processing afforded by the CAS may be the basis for declarative memory. In fact, Squire, Shimamura, and Amaral (in press) have suggested that the hippocampal formation may contribute to memory by providing the basis for "conjunctions." Although this notion has not been spelled out in any detail, it may be similar to our view of the CAS.

There are both subtle and obvious differences between our theory and those just mentioned. However, it is perhaps more important to note that there is considerable basic agreement among many recent formulations (Eichenbaum, Fagan, \& Cohen, 1986; Gage, 1985; Nadel \& Willner, 1980; Nadel, Willner, \& Kurz, 1985; O'Keefe \& Nadel, 1978; Squire, Shimamura, \& Amaral, in press; Teyler \& DiScenna, 1986; Wickelgren, 1979). They agree in that the hippocampal formation is posited as being critically involved in storing some form of relational information, even though they differ with respect to the kind of relational information that is fundamental and with respect to where the representation of relational information is stored.

There are, of course, at least two notable exceptions: the working memory theory of Olton et al. (1979), and Rawlins' (1985) view of the hippocampus as a temporary memory buffer. Neither of these theories assigns any special importance to the hippocampus as a storage site for relational information. We also think that neither of these theories at this point fares very well in integrating the literature. However, this is not the place to critically review the literature in relationship to them.

\section{CONCLUSION AND PROSPECTUS}

We have attempted to provide a theoretical framework that integrates a wide range of data relating the hippo- 
campal formation to learning and memory. We leave it to the reader to judge how successful our attempt at a synthesis has been. In our view, however, the success of this effort resides not just in how well it organizes the past but more importantly in how well it provides a map for future research. Thus we will end by discussing the future.

First, we note that the theory is quite testable. Its primary prediction is that animals with hippocampalformation damage will be seriously impaired on any behavioral task that has no simple association solution. We have presented some new data to support this assertion: the results of the negative patterning discrimination problem. Data from more problems of this sort must be gathered, however, to confirm our position. There are many ways this can be done. Earlier, we described an example in which the animal was rewarded for responding in the presence of one auditory stimulus, A1, and nonrewarded in the presence of A2 in the presence of a light (light: $A 1+/ A 2-)$, but the contingencies were reversed when the conditioning chamber was dark (dark: A1-/ $\mathrm{A} 2+$ ). Such a problem cannot be solved on the basis of simple associations, and there are many variations on this problem that can be arranged with stimuli from a variety of modalities.

We, like others, have proposed that at least two learning and memory systems are engaged when the organism interacts with its world. For us, they are the SAS and CAS. One of the most intriguing problems for future work is to gain some detailed understanding of how these two systems interact. We have assumed that both systems acquire information in parallel in the normal animal, and that control over performance by the SAS can be suppressed in many situations by the CAS. If the latter assumption is correct, then how does hippocampal formation exert this inhibitory effect? What are the particular task demands that determine when the CAS exerts its inhibitory influence over the SAS?

In conclusion, we have offered a fresh interpretation of the hippocampal formation's contribution to learning and memory-an interpretation that provides a conceptual basis for sorting memory processes into hippocampaldependent and hippocampal-independent categories. The position is congruent with certain ideas in the traditional animal learning area, and it has similarities with certain other contemporary views of hippocampal function. We have illustrated how the configural association formulation can be applied to a variety of types of learning and memory experiments. We have advocated that there are advantages of this position over other theories, and we believe that further experimental tests of the predictions basic to the theory will bring us much closer to an understanding of the essential contribution of the hippocampal formation to learning and memory.

\section{REFERENCES}

Ackley, D. H., Hinton, G. E., \& Sejnowski, T. J. (1985). A learning algorithm for Boltzmann machines. Cognitive Science, 9, 147-169. Aggleton, J. P., Hunt, P. R., \& Rawlins, J. N. P. (1986). The ef- fects of hippocampal lesions upon spatial and non-spatial tests of working memory. Behavioural Brain Research, 19, 133-146.

Aggleton, J. P., Mishinin, M. (1985). The amygdala: Sensory gateway to emotions. In R. Plutchik \& H. Kellerman (Eds.), Emotion: Theory, research, and experience (Vol. 3, pp. 281-299). New York: Academic Press.

AMSEL, A. (1958). The role of frustrative nonreward in noncontinuous reward situations. Psychological Bulletin, 55, 102-119.

AMSEL, A. (1962). Frustrative nonreward in partial reinforcement and discrimination learning. Psychological Review, 69, 306-328.

Bachevalier, J., Saunders, R. C., \& Mishioin, M. (1985). Visual recognition in monkeys: Effects of transection of fornix. Experimental Brain Research, 57, 547-553.

Bagshaw, M. H., Benzies, S. (1968). Multiple measures of the orienting reaction and their dissociation after amygdalectomy in monkeys. Experimental Neurology, 20, 175-187.

Bagshaw, M. H., \& Coppock, H. W. (1968). Galvanic skin response conditioning deficit in amygdalectomized monkeys. Experimental Neurology, 20, 188-196.

BARNes, C. A. (1988). Spatial learning and memory processes: The search for their neurobiological mechanisms in the rat. Trends in Neurosciences, 11, 163-169.

BARTo, A. G. (1985). Learning by statistical cooperation of selfinterested neuron-like computing elements (COINS Technical Report No. 85-11). Amherst, MA: University of Massachusetts, Department of Computer and Information Science.

Bellingham, W. P., Gillette-Bellingham, K., \& Kehoe, E. J. (1985). Summation and configuration in patterning schedules with the rat and rabbit. Animal Learming \& Behavior, 13, 152-164.

Berger, T. W., \& OrR, W. B. (1983). Hippocampectomy selectively disrupts discrimination reversal learning of the rabbit nictitating membrane response. Behavioural Brain Research, 8, 49-68.

Best, P. J., \& ORR, J., JR. (1973). Effects of hippocampal lesions on passive avoidance and taste aversion conditioning. Physiology \& Behavior, 10, 193-196.

COHEN, N. J., \& SuIRe, L. R. (1980). Preserved learning and retention of pattern analysing skill in amnesia: Dissociation of knowing how and knowing that. Science, 210, 207-209.

Douglas, R. J. (1967). The hippocampus and behavior. Psychological Bulletin, 67, 416-442.

Douglas, R. J., \& Pribram, K. H. (1966). Learning and limbic lesions. Neuropsychologia, 4, 197-220.

Eichenbaum, H., Fagan, A., \& Cohen, N. J. (1986). Normal olfactory discrimination learning set and facilitation of reversal leaming after medial-temporal damage in rats: Implications for an account of preserved learning abilities in amnesia. Jourmal of Neuroscience, 6 , 1876-1884.

GAFFAN, D. (1974). Recognition impaired and association intact in the memory of monkeys after transection of the fornix. Journal of Comparative \& Physiological Psychology, 86, 1100-1109.

GAFFAN, D., \& HARRISON, S. (1984). Reversal learning by fornix transected monkeys. Quarterly Joumal of Experimental Psychology, 36, 223-234.

Gaffan, D., Saunders, R. C., Gaffan, E. A., Harrison, S., SHIElDs, C., OWEN, M. J. (1984). Effects of fornix transection upon associative memory in monkeys: Role of the hippocampus in learned action. Quarterly Journal of Experimental Psychology, 36, 173-221.

GAGE, P. D. (1985). Preserved and impaired information processing systems in human bilateral amnesiacs and infrahuman analogues: Role of hippocampectomy. Joumal of Mind \& Behavior, 4, 515-552.

GodDard, G. V. (1964). Functions of the amygdala. Psychological Bulletin, 62, 89-109.

Grossierg, S. (1982). Studies of mind and brain: Neural principles of leaming, perception, development, cognition, and motor control. Boston: Reidel Press.

HIRSH, R. (1974). The hippocampus and contextual retrieval of information from memory: A theory. Behavioral Biology, 12, 421-444.

HiRsH, R. (1980). The hippocampus, conditional operations and cognition. Physiological Psychology, 8, 175-182.

Hursh, R., Leber, B., Gruman, K. (1978). Fornix fibers and motiva- 
tional states as controllers of behavior: A study stimulated by the contextual retrieval theory. Behavioral Biology, 22, 463-478.

Hsiso, S., \& IsaAcson, R. L. (1971). Learning of food and water positions by hippocampus damaged rats. Physiology \& Behavior, 6, 81-83.

Hull, C. L. (1942). Principles of behavior. New York: AppletonCentury-Crofts.

JARRARD, L. E. (1983). Selective hippocampal lesions and behavior: Effects of kainic acid lesions on performance of place and cue tasks. Behavioral Neuroscience, 97, 873-889.

JARRARD, L. E. (1986). Selective hippocampal lesions and behavior: Implications for current research and theorizing. In R. L. Isaacson \& K. H. Pribram (Eds.), The hippocampus (Vol. 4, pp. 93-127). New York: Plenum.

JarRard, L. E., Okaichi, H., Goldschmidt, R., \& Stewart, O. (1984). On the role of the hippocampal connections in the performance of place and cue tasks: Comparison with damage to the hippocampus. Behavioral Neuroscience, 98, 946-954.

JoNES, B., \& MishKiN, M. (1972). Limbic lesions and the problem of stimulus-reinforcement associations. Experimental Neurology, 36, 362-377

Kamin, L. J. (1969). Predictability, surprise, attention, and conditioning. In B. A. Campbell \& R. M. Church (Eds.), Punishment and aversive behavior. New York: Appleton-Century-Crofts.

Kaye, H., PEarce, J. M. (1987). Hippocampal lesions attenuate latent inhibition and the decline of the orienting response in rats. Quarterly Journal of Experimental Psychology, 39B, 107-125.

Kaye, H., Preston, G. C., Szabo, L., Druiff, H., \& MackinTOSH, N. J. (1987). Context specificity of conditioning and latent inhibition: Evidence for a dissociation of latent inhibition and associative interference. Quarterly Journal of Experimental Psychology, 39B, $127-145$

KEHOE, E. J. (1988). A layered network model of associative learning: Learning-to-learn and configuration. Psychological Review, 95, 411-433.

KIMBLE, D. P. (1963). The effects of bilateral hippocampal lesions in rats. Journal of Comparative \& Physiological Psychology, 56, 273-283.

Luвow, R. E. (1973). Latent inhibition. Psychological Bulletin, 79, 398-407.

MacKintosh, N. J. (1975). A theory of selective attention: Variation in the associability of stimuli with reinforcement. Psychological Review, 82, 276-298.

MAHUT, H. (1971). Spatial and object reversal learning in monkeys with partial temporal lobe ablations. Neuropsychologia, 9, 409-424.

MAhUT, H., \& CoRdeAU, J. P. (1963). Spatial reversal deficit in monkeys after amygdalohippocampal ablations. Experimental Neurology, 7, 426-434.

Mahut, H., \& Moss, M. (1986). The monkey and the sea horse. In R. L. Isaacson \& K. H. Pribram (Eds.), The Hippocampus: (Vol. 4, pp. 241-279). New York: Plenum.

Mahut, H., Moss, M., \& Zola-Morgan, S. (1981). Retention deficits after combined amygdala-hippocampal and selective lesions in the monkey. Neuropsychologia, 19, 201-225.

Mahut, H., Zola-Morgan, S., Moss, M. (1982). Hippocampal lesions impair associative learning and memory in the monkey. Journal of Neuroscience, 2, 1214-1229.

MCNAughton, B. L. (1989). Neuronal mechanisms for spatial computation and information storage. In L. Nadel, L. Cooper, P. Culicover, \& R. M. Harnish (Eds.), Neural connections and mental computations (pp. 285-350). Cambridge, MA: MIT Press/Bradford Books.

MiLNER, B. (1959). The memory defect in bilateral hippocampal lesions. Psychiatric Research Reports, 11, 43-52.

Milner, B. (1962). Les troubles de la memoire accompagnant des lesions hippocampiques bilaterales. In P. Passouant (Ed.), Physiologie de l'hippocampe (pp. 257-272). Paris: Centre National de la Recherche Scientifique.

MILNER, B. (1970). Memory and the medial temporal regions of the brain. In K. H. Pribram \& D. E. Broadbent (Eds.), Biology of memory (pp. 29-50). New York: Academic Press.
Misukin, M. (1978). Memory in monkeys severely impaired by combined but not by separate removal of amygdala or hippocampus. Nature, 273, 297-298.

Mishin, M., Malamut, B., Bachevalier, J. (1984). Memories and habits: Two neural systems. In G. Lynch, J. L. McGaugh, \& N. M. Weinberger (Eds.), Neurobiology of learning and memory (pp. 65-88). New York: Guilford Press.

Mishrun, M., \& Petri, H. L. (1984). Memories and habits: Some implications for the analysis of learning and retention. In L. R. Squire \& N. Butters (Eds.), Neuropsychology of memory (pp. 287-296). New York: Guilford Press.

MorRIs, R. G. M. (1981). Spatial localization does not require the presence of local cues. Learning \& Motivation, 12, 239-260.

Morris, R. G. M., Garrud, P., Rawlins, J. N. P., \& O'KeEfe, J. (1982). Place navigation impaired in rats with hippocampal lesions. Nature, 297, 681-683.

Moss, M., Mahut, H., \& Zola-Morgan, S. (1981). Concurrent discrimination learning of monkeys after hippocampal, entorhinal, or fornix lesions. Journal of Neuroscience, 1, 222-240.

MURRAY, E. A., \& MISHKIN, M. (1984). Severe tactual as well as visual memory deficits following combined removal of the amygdala and hippocampus in monkeys. Journal of Neuroscience, 4, 2565-2580.

NACHMAN, M., AshE, J. H. (1974). Effects of bilateral amygdala lesions on neophobia, learned taste aversions, and sodium appetite in rats. Journal of Comparative \& Physiological Psychology, 80, 622-643.

Nadel, L., MacDonald, L. (1980). Hippocampus: Cognitive map or working memory? Behavioral \& Neural Biology, 29, 405-409.

NADEL, L., O'KeEFe, J. (1974). The hippocampus in pieces and patches: An essay on modes of explanation in physiological psychology. In R. Bellairs \& J. Gray (Eds.), Essays on the nervous system: A festschrift for Professor J. Z. Young (pp. 367-390). Oxford, England: Clarendon Press.

NAdel, L., \& Willner, J. (1980). Context and conditioning: A place for space. Physiological Psychology, 8, 218-228.

Nadel, L., Willner, J., Kurz, E. (1985). Cognitive maps and environment context. In P. D. Balsam \& A. Tomie (Eds.), Context and learning (pp. 385-406). Hillsdale, NJ: Erlbaum.

ODLING-SmeE, F. J. (1975). The role of background stimuli during Pavlovian conditioning. Quarterly Journal of Experimental Psychology, 27, 201-209.

OKAICHI, H. (1987). Performance and dominant strategies on place and cue tasks following hippocampal lesions in rats. Psychobiology, 15, 58-63.

OKKEEFE, J., NADEL, L. (1978). The hippocampus as a cognitive map. Oxford, England: Clarendon Press.

O'KeEFe, J., \& NADEL, L. (1979). Precis of O'Keefe \& Nadel's "'The hippocampus as a cognitive map." Brain \& Behavioral Sciences, 2 , 487-533.

O'Keefe, J., Nadel, L., Keightly, S., \& KILl, D. (1975). Fornix lesions selectively abolish place learning in the rat. Experimental Neurology, 48, 152-166.

Olton, D. S., Becker, J. T., \& HandelmanN, G. E. (1979). Hippocampus, space and memory. Behavioral \& Brain Sciences, 2, 313-365.

OLTON, D. S., FEUSTLE, W. (1981). Hippocampal function and nonspatial memory. Experimental Brain Research, 411, 380-389.

Olton, D. S., PAPAS, B. C. (1979). Spatial memory and hippocampal function. Neuropsychologia, 17, 669-682.

Olton, D. S., \& SAMUELSON, R. J. (1976). Remembrance of places passed: Spatial memory in rats. Journal of Experimental Psychology: Animal Behavior Processes, 2, 97-116.

Parkinson, J. K., MishKIN, M. (1982). A selective role for the hippocampus in monkeys: Memory for the location of objects. Society of Neuroscience Abstracts, 23.

Parkinson, J. K., Murray, E. A., \& Mishrin, M. (1988). A selective mnemonic role for the hippocampus in monkeys: Memory for the location of objects. Journal of Neuroscience, 8, 4159-4167.

RAffaele, K. C., \& Olton, D. S. (1988). Hippocampal and amygdala involvement in working memory for nonspatial stimuli. Behavioral Neuroscience, 102, 349-355.

Rawlins, J. N. P. (1985). Associations across time: The hippocampus 
as a temporary memory store. Behavioral \& Brain Sciences, 8 , 479-496.

Rescorla, R. A. (1972). "Configural" conditioning in discrete-trial bar pressing. Journal of Comparative \& Physiological Psychology, 79, 307-317.

Rescorla, R. A., \& Wagner, A. R. (1972). A theory of Pavlovian conditioning: Variations in the effectiveness of reinforcement and nonreinforcement. In A. H. Black \& W. F. Prokasy (Eds.), Classical conditioning: II. Current research and theory (pp. 64-99). New York: Appleton-Century-Crofts.

Restle, F. (1957). Discrimination of cues in mazes: A resolution of the "place-vs-response" question. Psychological Review, 64, 217-228.

Rickert, E. J., Bennett, T. L., LANe, P., \& French, J. (1978). Hippocampectomy and the attenuation of blocking. Behavioral Biology, 22, $147-160$

Rickert, E. J., Lorden, J. F., Dawson, R., Jr., Smyly, E., \& Callahan, M. F. (1979). Stimulus processing and stimulus selection in rats with hippocampal lesions. Behavioral \& Neural Biology, 27, 454-465.

Rolss, E. T., \& Rol.Ls, B. J. (1973). Altered food preferences after lesions in the basolateral region of the amygdala in the rat. Journal of Comparative \& Physiological Psychology, 83, 248-259.

Ross, R. T., OrR, W. B., Holland, P. C., Berger, T. W. (1984). Hippocampectomy disrupts acquisition and retention of learned conditional responding. Behavioral Neuroscience, 98, 211-225.

Rudy, J. W., Sutherland, R. J. (in press). The hippocampal formation is necessary for rats to learn and remember configural discriminations. Behavioural Brain Research.

Rumelhart, D. E., Hinton, G. E., \&iluams, R. J. (1986). Leaming internal representations by error propagation. In D. E. Rumelhart \& J. L. McClelland (Eds.), Parallel distributed processing: Explorations in the microstructure of cognition: Vol. 1. Foundations (pp. 318-362). Cambridge, MA: MIT Press.

Salmon, D., Zola-Morgan, S., \& Suire, L. R. (1987). Retrograde amnesia following combined hippocampal-amygdala lesions in monkeys. Psychobiology, 15, 37-47

Saunders, R. C., Murray, E. A., a Mishkin, M. (1984). Further evidence that amygdala and hippocampus contribute equally to visual recognition. Neuropsychologia, 22, 785-796.

SCoville, W. B., MiLNer, B. (1957). Loss of recent memory after bilateral hippocampal lesions. Joumal of Neurology, Neurosurgery \& Psychiatry, 20, 11-21.

Solomon, P. R. (1977). Role of hippocampus in blocking and conditioned inhibition of the rabbit's nictitating membrane response. Journal of Comparative \& Physiological Psychology, 91, 407-417.

SOLOMON, P. R., \& MOORE, J. W. (1975). Latent inhibition and stimulus generalization of the classically conditioned nictitating membrane response in rabbits (Oryctolagus cuniculus) following dorsal hippocampal ablation. Journal of Comparative \& Physiological Psychology, 89, 1192-1203.

SPENCE, K. W. (1936). The nature of discrimination learning. Psychological Review, 43, 427-449.

SQUIRE, L. R. (1987). Memory and brain. New York: Oxford University Press.

SQuire, L. R., \& COHEN, N. J. (1984). Human memory and amnesia. In G. Lynch, J. L. McGaugh, \& N. M. Weinberger (Eds.), Neurobiology of learning and memory (pp. 3-64). New York: Guilford Press.

SQuire, L. R., Cohen, N. J., \& NADEL, L. (1984). The medial temporal region and memory consolidation: $A$ new hypothesis. In H. Weingartner \& W. Parker (Eds.), Memory consolidation (pp. 185210). Hillsdale, NJ: Erlbaum.

Squire, L. R., Shimamura, A. P., \& Amaral, D. G. (in press). Memory and the hippocampus. In J. Byrne \& W. Berry (Eds.), Neural models of plasticity. New York: Academic Press.

SQUIRE, L. R. \& Zola-Morgan, S. (1983). The neurology of memory: The case for correspondence between the findings for human and nonhuman primates. In J. A. Deutsch (Ed.), The physiological basis of memory (2nd ed., pp. 199-267). New York: Academic Press.
SUTHERLAND, R. J. (1985). The navigating hippocampus: An individual medley of space, memory and movement. In G. Buzsaki \& C. H. Vanderwolf (Eds.), Electrical activity of the archicortex (pp. 255-279). Budapest: Akadémiai Kiadó.

Sutherland, R. J., ARnold, K. A., \&odriguez, A. R. (1987). Anterograde and retrograde effects on place memory after limbic or diencephalic damage. Society of Neuroscience Abstracts, 13, 1066. SutherLand, R. J., Kolb, B., \& Whishaw, I. Q. (1982). Spatial mapping: Definitive disruption by hippocampal or medial frontal cortical damage in the rat. Neuroscience Letters, 31, 271-276.

SUtherland, R. J., Whishaw, I. Q., \& KolB, B. (1983). A behavioural analysis of spatial localization following electrolytic, kainate-, or colchicine-induced damage to the hippocampal formation in the rat. Behavioural Brain Research, 7, 133-153.

Teitelbaum, H. A. (1964). A comparison of orbito-frontal and hippocampal lesions upon discrimination learning and reversal in the cat. Experimental Neurology, 90, 452-462.

TEYler, T. J., \& DiSCENNA, P. (1986). The hippocampal memory indexing theory. Behavioral Neuroscience, 100, 147.

ThoRNDIKE, E. L. (1898). Animal intelligence: An experimental study of the associative processes in animals. Psychological Monographs, 2(Whole No. 8).

Wagner, A. R., Logan, F. A., Haberlandt, K., \& Price, T. (1968) Stimulus selection in animal discrimination learning. Joumal of Experimental Psychology, 76, 171-180.

WhitLow, J. W., JR., \& WAGNER, A. R. (1972). Negative patterning in classical conditioning: Summation of response tendencies to isolable and configural components. Psychonomic Science, 27, 299-301.

WiCKelgren, W. A. (1979). Chunking and consolidation: A theoretical synthesis of semantic networks, configuring, S-R versus cognitive learning, normal forgetting, the amnesic syndrome, and the hippocampal arousal system. Psychological Review, 86, 44-60.

WILSON, F. A. W., RoLLs, E. T. (1987). Habituation and stimulusspecific neuronal responses recorded from the amygdala of the monkey. Society for Neuroscience Abstracts, 13, 1101

WINocur, G. (1980). The hippocampus and cue utilization. Physiological Psychology, 8, 280-288.

Winocur, G., Rawuins, J. N. P., Gray, J. A. (1987). The hippocampus and conditioning to contextual cues. Behavioral Neuroscience, 101, 617-627.

WoOdBury, C. B. (1943). The learning of stimulus patterns by dogs. Journal of Comparative \& Physiological Psychology, 35, 20-40.

Zola-Morgan, S., \&Quire, L. R. (1986). Memory impairment in monkeys following lesions limited to the hippocampus. Behavioral Neuroscience, 100, 155-160.

Zola-Morgan, S., SQuire, L. R., \& Amaral, D. (1986). Human amnesia and the medial temporal region: Enduring memory impairment following a bilateral lesion limited to the CAl field of the hippocampus. Journal of Neuroscience, 6, 2950-2967.

Zola-Morgan, S., Squire, L. R., Mishkin, M. (1982). The neuroanatomy of amnesia: Amygdala-hippocampus versus temporal stem. Science, 218, 1337-1339.

\section{NOTE}

1. If the distinction between simple associations and configural associations is to be useful, it may be helpful to specify a set of operations for distinguishing among stimuli that have entered into configural associations and those that are participating in simple associations. In principle, any elemental stimulus can enter into a configural association. Any stimulus has a number of different physical dimensions or features (e.g., size, color, shape, rate, etc.). To determine whether a particular feature is an elemental stimulus, one must demonstrate that the probability or strength of some response changes systematically if the value of that feature is varied. A similar operation can determine whether a particular stimulus event is composed of two or more independent features (e.g., AB). One can place a particular response under the control of one feature, $\mathrm{A}$, by reinforcing that response in the presence 
of one value of $A$ and nonreinforcing that response in the presence of another value of $A$, while holding the value of $B$ constant. Then the same response can be placed under the differential control of two values of $B$ while the value of $A$ is held constant. If these operations are successful, a compound stimulus composed of two elementary stimuli has been identified. To demonstrate that these two elemental stimuli, A and B, can enter into a configural association, one must now show that the subject can respond differentially to the compound stimulus $\mathrm{AB}$ and its elements. This can be done by demonstrating that the subject can learn one response, $R 1$, in the presence of $A B$, and a different response, $R 2$, in the presence of the A and B elements, where R1 and R2 are incompatible.

(Manuscript received June 24, 1988: revision accepted for publication December 28, 1988.)

\section{The Mesolimbic Dopamine System: From Motivation to Action An International Workshop Malta} September 25-29, 1989

An international workshop on the Mesolimbic Dopamine System (From Motivation to Action) will be held, under the auspices of the European Behavioural Pharmacology Society, in Malta during the week of September 25-29, 1989.

Participating invited speakers include Ahlenius, Beninger, Bozarth, Buchsbaum, Carlsson, Cools, Cooper, Di Chiara, Fibiger, Goldman-Rakic, Groenewegen, Koob, LeMoal, Mogenson, Nielsen, Phillips, Post, Robbins, Sahakian, Scheel-Krüger, Stinus, White, Willner, and Zacharko.

The invited lectures on Day 1 will be devoted to the behavioral pharmacology of mesolimbic dopamine; on Day 2, to the structure and function of the mesolimbic system; and, on Day 3, to mesolimbic dysfunction.

Posters are invited on any topic structurally or functionally related to mesolimbic dopamine.

For further information, please contact Professor P. Willner, Psychology Department, City of London Polytechnic, Old Castle Street, London E1 7NT, U.K. 